\title{
Tristana Reluz y María Eugenia Alonso, pianistas: notas sobre la función de la música en Tristana de Benito Pérez Galdós e Ifigenia de Teresa de la Parra
}

Joan Antoni Forcadell

Forcadell, J. A. (2022). Tristana Reluz y María Eugenia Alonso, pianistas: notas sobre la función de la música en Tristana de Benito Pérez Galdós e Ifigenia de Teresa de la Parra. Revista de Filología y Lingüística de la Universidad de Costa Rica, 48(1), e48025. doi: https://doi.org/10.15517/rfl.v48i1.48025

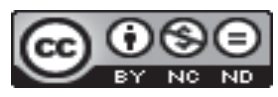

Doi: https://doi.org/10.15517/rfl.v48i1.48025

URL: https://revistas.ucr.ac.cr/index.php/filyling/index 
Revista de Filología y Lingüística de la Universidad de Costa Rica

ISSN: 0377-628X

ISSN: 2215-2628

filyling@gmail.com

Universidad de Costa Rica

Costa Rica

\title{
Tristana Reluz y María Eugenia Alonso, pianistas: notas sobre la función de la música en Tristana de Benito Pérez Galdós e Ifigenia de Teresa de la Parra
}

\author{
Forcadell, Joan Antoni \\ Tristana Reluz y María Eugenia Alonso, pianistas: notas sobre la función de la música en Tristana de Benito \\ Pérez Galdós e Ifigenia de Teresa de la Parra \\ Revista de Filología y Lingüística de la Universidad de Costa Rica, vol. 48, núm. 1, e48025, 2022 \\ Universidad de Costa Rica, Costa Rica \\ Disponible en: https://www.redalyc.org/articulo.oa?id=33268016002 \\ DOI: https://doi.org/10.15517/rfl.v48i1.48025
}

\section{(c) $(1) \Theta$}

Esta obra está bajo una Licencia Creative Commons Atribución-NoComercial-SinDerivar 3.0 Internacional. 


\section{Tristana Reluz y María Eugenia Alonso, pianistas: notas sobre la función de la música en Tristana de Benito Pérez Galdós e Ifigenia de Teresa de la Parra}

Tristana Reluz and María Eugenia Alonso, Pianists: Notes on The Role of Music in Tristana by Benito Pérez Galdós and Ifigenia by Teresa De La Parra

Joan Antoni Forcadell

Universidad Autónoma de Barcelona, Barcelona, España

joanantoniforcadell@gmail.com

DOI: https://doi.org/10.15517/rfl.v48i1.48025

Redalyc: https://www.redalyc.org/articulo.oa?

(D) https://orcid.org/0000-0001-5787-7741

Recepción: 05 Diciembre 2020

Aprobación: 09 Febrero 2021

\section{Resumen:}

Este artículo analiza cómo dos novelas publicadas en contextos distintos, Tristana (1892), de Benito Pérez Galdós, e Ifgenia (1924), de Teresa de la Parra, se sirven de la música para abordar la cuestión femenina en las respectivas sociedades en las que se insertan sus protagonistas. A partir de un análisis contrastivo, se señalan paralelismos constructivos que son fundamentales para desentrañar el sentido de sus discutidos desenlaces y que, en última instancia, permiten ver en la música un componente temático de primer orden en la articulación de sus respectivas estructuras narrativas. Tanto Tristana Reluz como María Eugenia Alonso ven en el desarrollo de sus dotes pianísticas una vía de profesionalización y emancipación que se ve frustrada por instancias y circunstancias ajenas a sus voluntades. Se concluye señalando trayectorias especulares ante encrucijadas similares, en ambos casos paradójicas: mientras que los conatos de rebelión en María Eugenia, encauzados mediante el arte, acaban siendo inocuos, y su integración en las instituciones sociales es plena, Tristana acaba desarrollando una personalidad artística arrolladora en un cuerpo mutilado que ha sufrido todas las transgresiones sociales posibles, pero su reintegración es imposible.

Palabras clave: Benito Pérez Galdós, Teresa de la Parra, música, cuerpo, mujer.

\section{Abstract:}

This article analyzes how two novels published in different contexts, Tristana (1892), by Benito Pérez Galdós, and Ifigenia (1924), by Teresa de la Parra, use music to address the women's issue in the respective societies in which its protagonists are inserted. Through a contrastive analysis, constructive parallels are pointed out that are fundamental to unravel the meaning of their disputed ends and that, ultimately, allow us to see in music a first-order thematic component in the articulation of their respective narrative structures. Both Tristana Reluz and María Eugenia Alonso see in the development of their piano skills a means of professionalization and emancipation that is frustrated by instances and circumstances beyond their control. We conclude by pointing out specular trajectories in the face of similar crossroads, in both cases paradoxical: while the attempts of rebellion in María Eugenia, channeled through art, end up being innocuous, and her integration into social institutions is complete, Tristana ends up developing an overwhelming artistic personality in a mutilated body that has suffered all possible social transgressions, but her reintegration is impossible.

KeYwords: Benito Pérez Galdós, Teresa de la Parra, music, body, woman.

\section{INTRODUCCIÓN}

"Pero yo pregunto: ¿es locura poseer un arte, cultivarlo y vivir de él?

¿Tan poco entiendo del mundo que tengo por posible lo imposible?”

Benito Pérez Galdós (Tristana, 1892, p. 90).

Las sendas por las que Galdós en Tristana y Teresa de la Parra en Ifigenia transitan en la exposición del “problema endiablado de la mujer libre" (Pérez Galdós, 2003, p. 91) no pudieran parecer, en un principio, más alejadas. Salvando las consabidas diferencias en el plano de la historiografía literaria, la ideología y el género, en el ámbito estrictamente textual el recorrido vital que describen ambas protagonistas es apenas equiparable: 
en gran medida, por todo lo relativo a las transgresiones sobre lo corporal de las que el personaje galdosiano es víctima, tanto por el régimen de barraganería al que se ve sometido desde temprana edad y la mutilación que sufre al final de la novela, así como por su condición social y la educación que recibe. En abstracción, sin embargo, el esquema no es tan disímil: dos jóvenes casaderas en situación de orfandad absoluta, adoptadas por individuos con quienes comparten relaciones de parentesco más o menos cercanas y con quienes -por su situación económica - se creen en deuda, en un momento determinado descubren el amor más allá de las imposiciones sociales y, finalmente, ven sus aspiraciones dramáticamente truncadas.

Quizás por ello la crítica, que ha evidenciado acusadas divergencias exegéticas en la valoración del desenlace de Tristana y María Eugenia como cifra del componente feminista atribuible a sendas obras, no ha señalado un punto de intersección por el que, desde perspectivas distintas, ambas dialogan: la función del arte en sus múltiples derivadas ya no solo en el desarrollo y articulación de la cuestión de la mujer, sino también como componente estructural narrativo ${ }^{1}$. A continuación, sin más ánimo que el de esbozar su desarrollo contrastivamente, se atiende a la música como una de las vertientes menos exploradas en las que son observables estos procesos y su imbricación discursiva en el desarrollo de la cuestión de la mujer.

\section{EsTADO DE LA CUESTIÓN: LECTURAS COMPLEMENTARIAS}

El andamiaje teórico que sustente una lectura contrastiva de ambas obras no puede tomar como válidas las mismas categorías analíticas en relación con sus respectivos personajes. La España finisecular y la Venezuela de principios de los años veinte del nuevo siglo comparten el progresivo afianzamiento del orden burgués como fruto de sus respectivas transformaciones económicas (Guerra de Avellaneda, 2009). Este sitúa al hombre como centro rector de la vida pública y se concreta en la familia en un sistema de valores que regula las dinámicas de lo privado en torno a la figura del ángel del hogar: ese "ángel de dulzura y de bondad" (Monlau, 1998, p. 389) que quintaesencia el ideal femenino maternal y abnegado, no definido "en sus vertientes ontológica y funcional, sino por el espacio que ocupa" (Aldaraca, 1992, p. 22), aunque sumido, como lamentaba Pardo Bazán (1998, p. 502), a "un destino de mera relación", carente de valor intrínseco, "sino en los otros, por los otros y para los otros".

Las aspiraciones de liberación por parte de Tristana y María Eugenia no se formulan en los mismos términos con respecto a este ideal por una cuestión de clase. En lo económico, la ruina de María Eugenia es requisito imprescindible para que la dependencia del núcleo familiar la obligue a renunciar progresivamente a sí misma, a sus valores de formación europea, y con ellos, a su libertad. Por su parte, Tristana nunca ha participado de ella puesto que ha vivido toda su vida alienada en esa dinámica de práctico vasallaje con respecto a don Lope, que la ha educado "para la ociosidad y para su propio recreo, a la turca verdaderamente" (Pérez Galdós, 2003, p. 65), asimilando como normales conductas sexuales aberrantes con respecto a los cánones burgueses, a los que no podrá ni siquiera corresponder como madre por la diferencia de edad entre ambos. El ángel del hogar es, por ello, un horizonte de expectativas al que ambas pueden corresponder de modo desigual.

Desde análisis independientes, tanto Aizenberg (1985) como Gold (1993) coinciden en señalar transgresiones del bildungsroman narrativo, nexo que vincularía a efectos estructurales ambas novelas y que reflejaría la progresión anticlimática propiciada por una ruptura de un estado previo de enajenación de la consciencia, al que sigue una incesante búsqueda de la identidad encauzada por medio de la escritura y del arte que, en distinto modo, se ve frustrada por una serie de condicionantes. En tal caso, la misma dimensión estructural incurre en autosabotaje pues nada de lo adquirido desde el plano vivencial o intelectual coadyuva la idea de progreso; la transformación en el fuero interno de los personajes los lleva a constatar, como advierte Guerra Cunningham (2004), su misma futilidad.

Haciendo hincapié sobre este movimiento de exploración y ensanchamiento de las dimensiones de la feminidad, destaca la lectura y la práctica de la escritura como territorio en el que tiene lugar esa "actividad 
imaginativa autorreflexiva" que representa la "lucha por conocerse" (Aizenberg, 1985, p. 543). Es mediante el género epistolar y, más tarde, con el diario personal, que María Eugenia -y en menor medida también Tristana con sus cartas a Horacio- va tejiendo esa individualidad que propicia cada vez más lo que se va a convertir en un efectivo desgarramiento "entre dualidades que no logran reconciliar" (Gomes, 2004, p. 53), el de las apariencias de la realidad externa, sinónimo de falsedad, con respecto a aquella verdad interna del espíritu de corte prácticamente romántico que debe, resignadamente, ir superponiendo máscaras para pervivir. Se produce, por todo ello, la resignificación de un espacio que en un principio "representa una ocupación aceptable, hasta elogiable", puesto que "la habilidad de componer una carta" es "parte integrante de la instrucción que debe recibir el género femenino" (Gold, 1993, p. 664), espacio que es empleado, justamente, para dinamitar ese orden impuesto.

No resulta extraño que sea en este punto de evidente confluencia donde los comentaristas de ambas obras manejen conceptos similares o incluso intercambiables: del mismo modo que "Tristana irá adoptando y cambiando identidades como si de trajes se tratara” (Ramírez López, 2009, p. 57), -a lo que, en cierto modo, contribuye el tanteo y perfeccionamiento de distintas posibilidades artísticas-, María Eugenia utiliza los referentes literarios que maneja -Cenicienta, Penélope, Julieta, las princesas de Perrault y finalmente Ifigenia- como "filtros para sus experiencias y como puntos de cristalización para su identidad" puesto que interpreta en su vida "los papeles sobre los cuales lee" (Aizenberg, 1985, p. 545)². Gullón (2007) y Ramírez López (2009) ven en el arte un vehículo de modelización identitaria a través de una vivencia subjetiva alterna y trascendente para el personaje galdosiano, sin perjuicio de que esta última crítica lo conciba como un ejercicio inocuo de evasión, fundado en ficciones de liberación que la misma Tristana alimenta y luego descompone como un retorno a su estado inicial.

Évora Rivero (2005) expresa, en términos de preservación y modelación de la imagen o cara social positiva como refuerzo de pertenencia al endogrupo, el trabajo de los agentes externos en la readaptación de María Eugenia, en cuanto a usos y costumbres, a los patrones exigidos por la sociedad burguesa caraqueña. Esa transformación es organizada y dirigida mediante la definición de los espacios que puede ocupar la mujer: ese triple encierro de "su cuarto, la casa y Caracas" al que alude Guerra de Avellaneda (2009), solo transgredido con la apertura de la ventana, que se dictamina cuando los límites espaciales han conseguido, mediante la privación de la libertad, la abnegación del personaje; es entonces cuando puede mostrarse en sociedad. El tránsito es incompleto si no se tiene en cuenta la aseveración de Miró (1993, p. 510) en relación con Tristana, igualmente extensible a María Eugenia; asegura que su "afán de libertad es [...] afán de saber" $\mathrm{y}$, necesariamente, la anulación de este último repercute en la desintegración del primero en tanto que el conocimiento es el único camino de acceso a una profesión que le garantice su sustento y, con él, su libertad. En última instancia, la similitud entre las dos es de índole económica: es el mismo régimen de dependencia de ambas muchachas con respecto de sus familiares - que se traduce en trabas en su más temprana formación-lo que las limita, porque no dejan de considerarse posesiones de la familia (véase Ramírez López, 2009 y Évora Rivero, 2005). Como bien observa Acker (1988, p. 77), en María Eugenia, al final, "talent and knowledge are only spiritual decorations and in no way can offer her the unthinkable reliance of a career", que es lo que acaba determinando su matrimonio con César Leal. Ese impulso autodidacta, como le ocurre a Tristana, es insuficiente para catapultarla profesionalmente.

Todas estas claves de lectura pueden quedar matizadas o incluso anuladas por lo que ha sido, quizás, el principal elemento de discusión desde las más tempranas reseñas hasta los estudios más recientes sobre estas obras: la valoración crítica del deterioro y posterior fracaso de los proyectos vitales de ambos personajes, lo cual es determinante para evaluar el alcance y calado de sus proclamas feministas. A modo de breviario, en buena parte de las investigaciones se hace eco de su propósito realista. Tanto es así que para Sinnigen (1992) - en quien el irónico desenlace de Tristana como "beata, casada y cocinera" (p. 1489) ahonda en el binomio realidad-apariencia- habría que remontarse al género utópico para poder leer en los tiempos de la Restauración la historia de una mujer en posición de plena igualdad e independencia con respecto del 
hombre. Ello no relativiza el alcance del feminismo galdosiano, según Ramírez López (2009), que abunda en el componente del influjo trágico del destino. En opinión de Pardo Bazán (1892), la explicación debe buscarse en las condiciones materiales de la escritura, con un Galdós sobrepasado por otros proyectos que llega solo a bosquejar el conflicto.

Desde esta misma perspectiva, los paradigmas aplicados en Ifigenia parten de las declaraciones de su misma autora, que se defendía de las acusaciones de incitación a la rebelión alegando que no es "tan perjudicial a las niñas de nuestra época por la sencilla razón de que no hace sino reflejarlas" (Teresa de la Parra, en Acker, 1988, p. 78). En todo caso, que su postura es moderada lo constata a lo largo de toda la obra la inexistencia, en el actual estado de cosas, de soluciones honradas para María Eugenia, por lo que, siguiendo a Truneau (2005, p. 133), "Teresa de la Parra hizo la historia de la mujer en busca de la independencia, no de la mujer liberada", porque ninguna de las salidas dentro del abanico que despliega representa una opción real. La "liberación femenina" queda, al final, "sólo en lo externo" (Truneau, 2005, p. 128), la moda. García Chichester (1998) añade a estas reflexiones que detrás de la novela existe una voluntad de describir el conjunto de realidades a menudo irreconciliables de las jóvenes criollas, más que de desarrollar narrativamente un conflicto psicológico individual, con el problemático encaje de "los modelos culturales y literarios de procedencia ultramarina" (p. 138) como telón de fondo.

Desde otra óptica, diferentes estudios coinciden a través de múltiples planteamientos en atenuar o incluso negar la adhesión autoral a los principios teóricos del feminismo. Devastador resulta el juicio de Percival (1990), que ve en las últimas páginas de Tristana un necesario correctivo no solo para la protagonista, sino también para don Lope, esas dos instancias que se separan de las medianías del orden burgués por la estela quijotesca "bajo la atracción de la desmesura y del idealismo, o mejor dicho, falsismo, siguiendo los caminos del egoísmo" (p. 157); esto le sirve a Gold (1993) para afirmar que estas tesis toman la forma de la parodia en la novela. El foco para Miró (1993), que se adhiere en parte a estos juicios, se encuentra, sin embargo, en "la burla de un mal entendido feminismo" (p. 521). En esta misma dirección, López Baralt (2016, p. 18) atribuye los vaivenes emocionales del personaje a un trastorno de "déficit de atención y regresión infantil, además de ser maniacodepresiva", diagnóstico del que se sirve para reafirmarse en la pasividad de la muchacha y su incapacidad para analizar, afrontar y transformar su realidad. A pesar del tono paródico del desenlace, esta estudiosa no duda de que es entendido como un final feliz por la pareja, en parte por la "aceptación de la realidad" (López Baralt, 2016, p. 30), aun habiendo puesto en entredicho la capacidad de Tristana de apercibirla. Un tanto desmarcada de esos cauces, para Mayoral (1989), la cuestión de género es colateral, un pretexto para vehicular una reflexión en clave existencial sobre la infelicidad, la incompletud y el fracaso humano.

Leyendo a Foley, García Chichester (1998) destaca en Ifigenia su naturaleza ambigua, acrecentada mediante la ironía y "la fragmentación de la personalidad de la heroína" (p. 131) como rasgo genérico de las tragedias en las que se inspira De la Parra para el sacrificio. Por su parte, Bohórquez (1997) entiende el sacrificio de María Eugenia como el paroxismo de su idiosincrasia narcisista, una suerte de martirio autocomplaciente. La lectura en clave existencial lleva a Lanieri (2002) a considerar que esa sociedad que ha de venir deberá definirse como una síntesis de la nueva consciencia y los valores tradicionales, y que es en la maternidad desde donde María Eugenia va a encontrar el único espacio posible desde el que llevar a cabo esa ansiada transformación.

\section{ANÁLISIS DEL TEMA}

Un piano arrinconado no es sino un mueble a expensas de la suciedad y el deterioro por el paso del tiempo. Josefina Reluz, como trasunto de la suciedad moral a la que se verá expuesta su hija, anticipada narrativamente por su monomanía por la limpieza, llega incluso a "deslucir los muebles" del hogar "a fuerza de agua y estropajo [...] y hasta el piano, por dentro y por fuera” (Pérez Galdós, 2003, p. 18). Aplicado a Tristana, el sustantivo 
muñeca (Pérez Galdós, 2003, pp. 8, 27, 28, 157, 158,163, 165) ${ }^{3}$, repetido hasta en siete ocasiones a lo largo de la novela, la equipara con el instrumento musical como objeto decorativo de belleza artificial, inorgánica, de utilidad pasiva, un pasatiempo sin más alma que la de quien se sirve de él para sus propios fines.

Aun cuando las manos de la mujer más virtuosa hicieran brotar de él las más excelsas melodías, la aparición a lo largo del siglo XIX del piano como parte habitual del mobiliario de los interiores de las incipientes clases medias había sido socialmente organizada, un resquicio perfectamente delimitado y controlado a través del que la voz silenciada de la mujer-objeto se tornaba por fin música:

En toda Europa, el piano se entendía como un indicador de refinamiento. Tocarlo era una de las “aptitudes" que hacían de una joven un buen partido. [...] Junto con el arpa, el piano era el instrumento físicamente más apropiado para las mujeres; los instrumentos de viento obligaban a fruncir los labios, los violines a contornear el cuerpo y los violonchelos a abrir las piernas, mientras que, para tocar el piano, había que sentarse con los pies juntos, conservando el decoro. [...] se consideraba que el piano era relativamente "fácil" y accesible para las mujeres, pues únicamente debían ser capaces de tocar las teclas correctas. No hay una forma fiable de medir el impacto que tuvo el piano en la vida de las mujeres, pero está claro que supuso un importante cambio cultural y social. Hasta entonces, habían sido los miembros silenciosos de la familia, dócilmente dedicadas a la costura en el salón, mientras que ahora adquirían un papel central en la creación de música dentro del hogar (Figes, 2020, p. 127).

Este instrumento es el detonante del primer gran choque ideológico entre María Eugenia y su abuela. Metafóricamente, el rebajamiento al que se ve sometida propicia también que la muchacha llegue a entender su situación como la de "un objeto fino y de lujo que se halla de venta en esta feria de la vida" (De la Parra, 2008, p. 207), carente de voluntad, que es observado y adquirido mediante una transacción económica, el matrimonio. Lo interesante del caso y que refuerza la fundamentación de su ideario en clave feminista es que su discurso toma por único principio válido la razón. En otras palabras: no existen argumentos racionales que justifiquen el rol subalterno de la mujer en la sociedad. Es por ello que, ante la prohibición de tocar el piano bajo el pretexto de que debe guardar estricto luto por la muerte de su padre, el pasaje deviene una disputa dialéctica que pone ante el espejo las contradicciones de esa tradición de la que tanto tía Clara como Abuelita se proclaman adalides. La "razón" que se atribuyen atañe al principio de lo "sagrado", puesto que "Un padre es algo muy grande" y, como buena hija, María Eugenia tiene que "tener sentimientos... [...] educar tu corazón” (De la Parra, 2008, p. 57). Ante la negativa, esta propone astutamente interpretar piezas respetuosas en su tono con el duelo, pero ni con esas: hay que mantener las formas, preservar esa imagen social que asegura el encaje de la unidad familiar en el orden establecido; el arte violenta esa esfera de lo privado, la expone: peligran las apariencias. A modo de contrarréplica, tras preguntarse “¡Pero qué tiene que ver el piano con mi corazón!” (De la Parra, 2008, p. 58), la joven carga contra dos de los puntales de la idiosincrasia de la clase acomodada venezolana: el de las convenciones - "Yo me río y me burlo de los vecinos" (De la Parra, 2008, p. 58) - y el de la religión, precisamente por su índole dogmática:

[...] yo no comprendo en absoluto qué relación lógica puede existir entre la muerte de papá y el piano de esta casa... ¡ «los sentimientos»!... ¡vaya con los sentimientos!, pues si la música se inventó precisamente para eso: ipara expresar los sentimientos! Dime si no, Abuelita, dime: ¿qué es por ejemplo, una elegía o una marcha fúnebre sino un sistema refinado, artístico y genial de dar un pésame [...] (De la Parra, 2008, p. 58).

Sentimiento, razón y arte no están reñidos ${ }^{4}$ siempre que la tradición quede excluida de la ecuación; así lo demuestra Abuelita, inflexible, que alienta a su nieta en última instancia a "fingir" (De la Parra, 2008, p. 58) a pesar de todo, porque en la escala de valores se antepone la mentira en sociedad a esa sinceridad que organiza la coherencia interna del ser.

En medio queda el problema de la educación como paso indispensable para la profesionalización de la mujer libre e independiente, uno de los motivos centrales de la reflexión que desarrollan ambos autores. En palabras de Saturna, "sólo tres carreras pueden seguir las que visten faldas: o casarse, [...] el teatro [...] o... no quiero nombrar lo otro” (Pérez Galdós, 2003, p. 30), quedando descartados todos los oficios liberales. Pero Tristana ha recibido, por vía materna, únicamente la "educación insustancial de las niñas que aprenden 
a llevar un buen yerno a casa, a saber: un poco de piano, el indispensable barniz de francés, y qué sé yo... tonterías" (Pérez Galdós, 2003, p. 89). No hay arte en esa música: apenas una habilidad mecánica, un adorno que sirve como carta de presentación en sociedad. Ramos Rodríguez (2016, p. 13) habla de "baños de cultura" en referencia a los viajes a Europa que las familias adineradas en Latinoamérica programaban para la educación de sus hijos. Durante esa etapa formativa, María Eugenia descubre sus dotes artísticas y una especial predisposición para la música cuando su profesor elogia "la finura de mi oído, diciendo además que mi mano era la mano larga y firme de los buenos pianistas" (De la Parra, 2008, p. 56).

No obstante, la emancipación por la vía artística se plantea como posibilidad en momentos narrativos prácticamente opuestos. Livingstone (1972) ya se percató de que solo cuando se constata que el amor no le va a propiciar esa vía de escape, con el enfriamiento de las relaciones con Horacio, entra en escena la eclosión artística polifacética de Tristana a través de breves pero intensas experiencias en la literatura, la interpretación teatral, la pintura y la música, mostrando en todas ellas excelentes dotes, lo que Percival (1990, p. 156) lee como un tránsito del erotismo al arte y una especie de "suicidio emocional" cuando finalmente el joven pintor la abandona. Con María Eugenia ocurre exactamente al revés: no es hasta que advierte como imposible la liberación por sus propios medios que empieza perfilar a Gabriel Olmedo, su único amor real, como posible solución. Solo a partir de esa asimetría en la dirección de los procesos y de la limitación física de Tristana, como más adelante se verá, se explica la disparidad en las expectativas que se fundan ambas muchachas. La joven venezolana diseña un programa que parece infalible:

— ¡Me entregaré al arte! [...] ¡Ah! sí; estudiaré el piano ocho, nueve o diez horas diarias. Gracias a mis naturales disposiciones desarrolladas así por un estudio paciente y metódico, en pocos años puedo llegar a ser una verdadera pianista; me presentaré al conservatorio, quizás obtenga un premio; obtenido el premio daré conciertos; los conciertos me darán renombre; este renombre puede llegar a ser universal; y entonces... ¿ por qué no?... ¡al igual de Teresa Carreño yo también conoceré el triunfo, las ovaciones y la gloria!... ¡eso es!... y para ello, me pondré a la obra sin tardar el próximo lunes... ¡no!... ¡mañana mismo!... ¡no!... iiya!! (De la Parra, 2008, p. 57).

Es interesante destacar la disposición para el esfuerzo por parte de María Eugenia, que la entiende como única vía hacia el éxito, así como que tome como referente a Teresa Carreño, figura controvertida en Venezuela por haberse divorciado hasta en tres ocasiones.

Sumado el veto a su ruina económica, el desamparo de la muchacha es total: “¡Por la mañana me quitan la fortuna; ahora, en la tarde me arrebatan la gloria!” (De la Parra, 2008, p. 59). Si bien es cierto que las aspiraciones son compartidas con Tristana, que "Creyose llamada a ser muy pronto una notabilidad, una concertista de primer orden” (Pérez Galdós, 2003, p. 176), en su situación, estas formulaciones no dejan de ser simples quimeras por más que llegue efectivamente a desarrollar "maravillosas aptitudes" que son "obra de un misterioso poder de adivinación, sólo concedido a las almas privilegiadas, para quienes el arte no tiene ningún secreto" (Pérez Galdós, 2003, p. 198), puesto que su minusvalía representa un escollo prácticamente tan insalvable como su condición de género.

Para Tristana, como le ocurre a María Eugenia con la lectura, el arte -y en concreto la música- constituye el vehículo para la creación de una realidad alterna disociada de lo material con la que consigue evadirse de su situación y en la que imprime y explora todas sus posibilidades ontológicas. Lo mismo ocurre con Horacio, su amante, en quien "proyecta [...] su interpretación del hombre ideal" (Ramírez López, 2009, p. 62). Así, cuando toca el órgano lo transforma prácticamente en extensión de sí misma "convirtiendo el grave instrumento en lenguaje de su propia alma". La disociación entre cuerpo y alma se torna armonía cuando "su rostro se transfiguraba adquiriendo celestial belleza; su alma se desprendía de todo lo terreno para mecerse en el seno pavoroso de una idealidad dulcísima" (Pérez Galdós, 2003, p. 198). La descripción que se obtiene de la única ocasión en toda la novela en la que María Eugenia toca el piano ofrece claves similares, si bien sirve para vincular además el motivo de la tentativa de acercamiento amoroso por parte de Gabriel Olmedo, quien canta mientras ella interpreta y forma "una mezcla de delicias [...] embriagadoras" (De la Parra, 2008, p. 141). También se siente María Eugenia elevada en espíritu, se genera tal comunión sensualista en contacto con el 
instrumento que "fue poco a poco levantando en mi alma una sutil polvareda de sensaciones misteriosas... rodeada por la sutil polvareda interior" (De la Parra, 2008, p. 140).

En todo caso, la vivencia corporal en Tristana a partir de su enfermedad connota con mucha más fuerza su forma de experimentar el arte. Si en un primer momento la fragmentación del cuerpo puede representar la destrucción de la posibilidad de la música como vía de acceso a esa realidad alterna de los ideales -que explica, en la escena de la intervención quirúrgica, su preocupación: "no me quiten también las manos, porque entonces... Nada, que no me dejo quitar esta mano; la agarro con la otra para que no me la lleven... y la otra la agarro con esta, y así no me llevan ninguna" (Pérez Galdós, 2003, pp. 167-168)-, en cambio, al final de la novela ese arte deviene "cosa inferior y de escasa valía"; se efectúa una "mudanza" del ideal "del hombre en Dios" que repercute a efectos narrativos en una fosilización del cuerpo, que pasa a formar "parte integrante del edificio y aun de la institución” (Pérez Galdós, 2003, p. 204) religiosa en la que sigue, años más tarde, regularmente interpretando sus salmodias.

No deja de ser curioso que en este terreno ambas obras jueguen con las expectativas lectoras de manera similar. Por un lado, en Tristana se menciona que la protagonista “[e]n el piano poseía [...] la instrucción elemental del colegio, suficiente para farfullar polkas y valses o alguna pieza fácil” (Pérez Galdós, 2003, p. 176); en cambio, acaba tocando un órgano y dominando el estilo litúrgico. Por el otro, María Eugenia, que maneja los referentes de la música romántica, se desenvuelve de maravilla en ese "danzón" con "alma y emociones de tango" (De la Parra, 2008, p. 140) que es el "Cielito lindo", es decir, música tradicional popular. Sin ánimo de forzar la exégesis, quizás haya que ver en ello un voluntario rebajamiento en consonancia con la progresión disfórica que describen estructuralmente ambos textos. Especialmente sugerente resulta el ejemplo del órgano, que cifra parte de la ambigüedad del fragmento porque permite una interpretación bivalente: la que remite al legado barroco, connotado positivamente, y la que remite a instancias más prosaicas, a la tradición áurea simbolizada en ese don Lope como figura decadente, en consonancia con el desarrollo por parte de Tristana al final de la novela de la más material de las artes, la culinaria. Por lo tanto, Galdós, en su visión de lo religioso, no estaría olvidando esa herencia krausista que impregnó sus novelas de tesis; no puede ser casual en una muchacha que se había llegado a sentir, bajo los efectos del cloroformo, "el mismo Beethoven, su corazón, su cuerpo" (Pérez Galdós, 2003, p. 167).

En el caso de María Eugenia, el desplazamiento mediante el arte la acerca a esa tradición no europea, genuinamente criolla, propiamente latinoamericana, cuyos valores acabará finalmente integrando. Obsérvese, asimismo, que no es ella quien elige tocar, no toma una postura activa: lo hace a petición de Mercedes Galindo de manera “muy dócil y complaciente” (De la Parra, 2008, p. 140), y que su interpretación motiva una escena de voyerismo por parte de su enamorado, que la rememoraría años más tarde de este modo, recordando en parte ese objeto de lujo al que aludía tiempo atrás la misma María Eugenia:

y allí, en la penumbra del piano, muy cerquita de mí, comenzaba a tocar, y sus manos unidas [...] corrían por los arpegios, [...] y cuando de pronto se quedaban desmayadas en un acorde, yo las veía y las besaba con los ojos pensando: «Tienen la melodía, la blancura y el desigual aleteo de los cisnes moribundos...». Y luego, además de las manos, aquellos brazos tan finos, y aquel cuello tan puro de líneas, y aquella cabeza linda, y aquella sonrisa de gloria, y toda aquella armonía suya junto a la armonía y junto a la voz del piano, que era como la voz de mi alma que se estaba muriendo de felicidad (De la Parra, 2008, pp. 265-266).

En el plano fisiológico, también se desgranan ciertas ideas en torno a la vocación artística que estaban a la orden del día en el pensamiento médico de la época. Parte de la literatura decimonónica se hace eco, ya desde que Flaubert publicara Madame Bovary, de la preocupación por el fastidio -derivado de la falta de ocupaciones de la mujer de clase media- como una de las causas del adulterio femenino. Las palabras de Horacio cuando le expone a don Lope su voluntad de regalarle el organillo a Tristana parecen ir en esta misma línea: "Mis propósitos son que se instruya en un arte en que pueda lucir y gastar ese caudal inmenso de fluido acumulado en su sistema nervioso, los tesoros de pasión artística, de noble ambición, que llenan su alma" (Pérez Galdós, 2003, p. 192). María Eugenia, que como se lee en el subtítulo de la obra escribe -y quiere tocar el piano- porque se fastidia, no quedará al final de la novela exenta de peligro. El matrimonio 
con César Leal certifica la ruptura del sujeto en los términos cuerpo-alma, sociedad-individuo, porque hay que suponer que el sacrificio de María Eugenia no implica una renuncia a sí misma ni una transformación, sino que constituye la imposición de una máscara más, la última. Con el cese de la escritura con las últimas líneas de la novela, el tedio va a ser absoluto, y las declaraciones de Teresa de la Parra van a sobrevolar como un riesgo más que potencial:

Los verdaderos enemigos de la virtud femenina no son los peligros a que pueda exponerla una actividad sana, no son los libros, ni las universidades, ni los laboratorios, ni las oficinas, ni los hospitales, es: la frivolidad, es el vacío mariposeo mundano con que la niña casadera, o la señora mal casada, educadas a la antigua y enfermas ya de escepticismo, tratan de distraer una actividad que encauzada hacia el estudio y el trabajo, podría haber sido mil veces más noble y santa (en Truneau, 2005, p. 132).

No es casual que la eclosión tardía del fervor artístico de Tristana tenga lugar de forma simultánea a la amputación de su pierna: es precisamente lo que posibilita la exploración de la identidad femenina y la creación de un espacio propio que la singulariza, que tenga lugar en una corporalidad limitada y, por lo tanto, incapaz de trascender, de mostrarse en sociedad, de presentarse como modelo y de lograr un cambio, en lo que constituye un claro movimiento de compensación que impide la desestabilización del sistema social. Lo debió de tener muy presente Pérez Galdós cuando decidió, como apunta Sinnigen (1992), indultar a don Lope, que en el borrador de la novela era quien sufría la mutilación tras enfermar de reuma, en detrimento de la joven, lo que pone de manifiesto que la integridad corporal femenina, en espíritu como el de Tristana, es cuanto menos peligrosa.

Ifigenia manifiesta una total coherencia con este principio cuando son las fuerzas sociales representadas en Abuelita y tía Clara las que limitan las posibilidades intelectuales de María Eugenia y anatemizan todos los valores en el sustrato de la educación recibida en Francia. Pero la muchacha venezolana estaría habilitada para una última subversión, definitiva y determinante, de la que parece privarse a Tristana, en aplicación del paradigma expuesto por Muraro (1994): la generación, en una forma de transgresión tácita que prolonga el orden simbólico de la madre como afirmación del sentido del ser. Si el arte fracasa como trasunto de lenguaje a través del cual la mujer desarrolla códigos para decirse a sí misma e integrarse al continuum de la matriz generadora, la maternidad, en cambio, es una lógica incorruptible e indeleble, aun cuando la suplantare genealógicamente la ley del Padre, en tanto que sustituye y restituye la "competencia lingüística" y "simbólica" (Muraro, 1994, p. 34) en los individuos que genera:

[s]aber hablar quiere decir, fundamentalmente, saber traer al mundo el mundo, y esto podemos hacerlo en relación con la madre, no separadamente de ella [...]. [...] la lengua que hablamos y nuestro saber hablar son fruto, no sólo del intercambio entre hablantes, sino también de un pacto con lo real que se contrata con la madre, intercambiando reconocimiento de autoridad por la «facultad de lenguaje» (Muraro, 1994, pp. 50-51).

Aun cuando todas las fuerzas e instituciones sociales limitaran, reprimieran o destruyeran todos sus conatos de liberación a través de la profesionalización artística, su orden simbólico permanecería en su progenie, que debería retomar la contienda. La tragedia de Tristana reside, precisamente, en la imposibilidad del último baluarte de sus aspiraciones, que sería, aplicando estas mismas categorías, la delegación del cometido en sus sucesores. Ese mismo proyecto tenía una clara resolución ante Horacio, a quien llega a discutir el nombre, en lo que no es solo un desafío a la institución familiar, sino también al sistema lingüístico como traducción del orden simbólico de la madre: "eso de tuyo no es tan claro [...]. [...] la Naturaleza me da más derechos que a ti... Y se llamará como yo, con mi apellido nada más” (p. 99). Paradójicamente, no es su minusvalía, la cual no la inutiliza para ese cometido, la que la aparta de este fin, sino la incapacidad física de don Lope, achacoso y bien entrado en la vejez -o así, al menos, cabría esperarlo-.

Recuperando el análisis de Asensi (2008), a la improductividad biológica de las relaciones sexuales entre Tristana y don Lope en un principio y matrimoniales en un último momento, como modo de subversión de las leyes del mercado, en última instancia podría aducirse que la ruptura del continuum maternal implica en 
sí misma un último y poderoso acto performativo que socava la única institución que parece preservarse, el matrimonio, cuando la vía estética e incluso la religiosa quedan desplazadas.

Con todo ello, la diferencia en la tentativa de ambas protagonistas es de grado: a pesar de la disparidad cualitativa de la formación recibida y de sus respectivas trayectorias vitales, María Eugenia muestra una conformidad mucho mayor y su rebeldía acaba siendo inocua, mientras que harán falta más que barreras sociales y físicas para frenar el impulso de Tristana, que acaba desarrollando una personalidad artística arrolladora, si bien en última instancia termina siendo una persona más dependiente que nunca. En definitiva, sumando a los argumentos textuales expuestos, la cercanía de los planteamientos de Benito Pérez Galdós y Teresa de la Parra, demostrada por la sistemática aplicación teórica de paradigmas de análisis intercambiables a lo largo de las distintas lecturas críticas de sendas obras, Tristana e Ifigenia se revelan como textos que, más allá de la conjetura de posibles influencias, merecen ser estudiados de manera contrastada y en extenso de aquí en adelante.

\section{BibLiografía}

Acker, B. (1998). Ifigenia: Teresa de la Parra's social protest. Letras femeninas, 14(1), 73-79.

Aizenberg, E. (1985). El “Bildungsroman” fracasado en Latinoamérica: el caso de Ifigenia, de Teresa de la Parra. Revista Iberoamericana, 51(132-133), 539-546.

Aldaraca, B. (1992). El Ángel del hogar: Galdós y la ideología de la domesticidad en España. Madrid: Visor.

Asensi, M. (2008). Unsex me here: Tristana y la pasión. Scriptura, (19-20), 111-140.

Bohórquez, D. (1997). Teresa de la Parra: el diálogo de géneros y la melancolía. Caracas: Monte Ávila Editores.

Chamberlin, V. (1985). The Sonata Form Structure of Tristana. Anales Galdosianos, 20(1), 83-95.

De la Parra, T. (2008). Ifigenia. Diario de una señorita que escribió porque se fastidiaba. (E. Garrels, ed.). Doral: Stockcero.

Évora Rivero, C. M. (2005). Imagen y territorialidad de lo femenino en Ifigenia de Teresa de la Parra. Lengua y Habla, 9(1), 27-37.

Figes, O. (2020). Los europeos. Tres vidas y el nacimiento de la cultura cosmopolita. Barcelona: Taurus.

García Chichester, A. (1998). El sacrificio de María Eugenia Alonso en Ifigenia de Teresa de la Parra. Revista de Literatura Hispanoamericana, (37), 123-138.

Gold, H. (1993). Cartas de mujeres y la mediación epistolar en Tristana. En Actas del Cuarto Congreso de Estudios Galdosianos (1990) (pp. 661-671). Las Palmas de Gran Canaria: Cabildo Insular.

Gomes, M. (2004). Ifigenia de Teresa de la Parra: Dictadura, poéticas y parodias. Acta Literaria, (29), 47-67.

González Subías, J. L. (2007). La extensión del Romanticismo en España. Cuadernos de Ilustración y Romanticismo, (15), 223-237.

Guerra Cunningham, L. (2004). Cuerpo de mujer y rituales del adorno en Ifigenia de Teresa de la Parra. Letras femeninas, 30(1), 129-140.

Guerra de Avellaneda, G. (2009). Ifigenia: la casa encerrada de una sociedad pacata. Reconfiguración social de la Venezuela de comienzos del siglo XX en los espacios de la novela de Teresa de la Parra. Nuevo Mundo, Mundos Nuevos. Recuperado de https://journals.openedition.org/nuevomundo/56138

Gullón, R. (2007). Introducción. En Tristana (pp. 7-28). Madrid: Editorial Pliegos.

Lanieri, M. C. (2002). El memorialismo discursivo en Ifigenia de Teresa de la Parra. En Atti del XXI Convegno Associazione Ispanisti Italiani: Salamanca 12-14 settembre 2002 (Vol. 1, pp. 323-333). Salamanca: AISPI.

Livingstone, L. (1972). The law of nature and women's liberation in Tristana. Anales Galdosianos, (7), 93-100. Recuperado de http://www.cervantesvirtual.com/obra/the-law-of-nature-and-womens-liberation-in-tristana$0 /$

López Baralt, M. (2016). Tristana y su interminable final. Revista de estudios hispánicos, 3(1),13-36. 
Mayoral, M. (1989). Tristana y Feíta Neiras, dos versiones de la mujer independiente. En Centenario de Fortunata y Jacinta (1887-1987) (pp. 337-344). Madrid: Universidad Complutense de Madrid. Recuperado de http://ww w.cervantesvirtual.com/obra/tristana-y-feta-neiras-dos-versiones-de-la-mujer-independiente-0/

Miró, E. (1993). Tristana o la imposibilidad de ser. Cuadernos Hispanoamericanos, (250-252), 505-522.

Monlau, P. F. (1998). Higiene del matrimonio (1853) (fragmento). En A. Blanco, C. Enríquez de Salamanca y C. Jagoe (Eds.), Los discursos de género. Textos y contextos en el siglo XIX (pp. 386-397). Barcelona: Icaria.

Muraro, L. (1994). El Orden simbólico de la madre. Madrid: Horas y Horas.

Pardo Bazán, E. (1892). Tristana. Nuevo Teatro Critico, (17), 77-90. Recuperado de http://www.cervantesvirtual.co $\mathrm{m} /$ obra-visor/nuevo-teatro-critico--40/html/02958176-82b2-11df-acc7-002185ce6064_80.html

Pardo Bazán, E. (1998). Una opinión sobre la mujer (1892) (fragmento). En La mujer en los discursos de género. Textos $y$ contextos en el siglo XIX (pp. 500-505). Barcelona: Icaria.

Percival, A. (1990). Personaje, espacio e ideología en Tristana. En Actas del Tercer Congreso Internacional de Estudios Galdosianos (1989) (pp. 151-158). Las Palmas de Gran Canaria: Cabildo Insular.

Pérez Galdós, B. (2003). Tristana. (M. Amores y A. Sánchez, eds.). Barcelona: Vicens Vives.

Ramírez López, M. (2009). Las fases de Tristana en la búsqueda de su identidad. Mester, 38(1), 57-66.

Ramos Rodríguez, F. (2016). Teresa de la Parra e Ifigenia (1924): Mujer y escritura. Folios, (43), 3-15.

Sinnigen, J. (1992). Tristana: la tentación del melodrama. En Actas del X Congreso de la Asociación Internacional de Hispanistas (pp. 1485-1490). Barcelona: Promociones y Publicaciones Universitarias.

Truneau Castillo, V. (2005). Confesión de rebeldía y sacrificio. Notas sobre Ifigenia, de Teresa de la Parra. Anales de Literatura Hispanoamericana, (34), 125-139.

\section{Notas}

1 Tirando del hilo temático musical, es cierto que Chamberlin (1985) desarrolla una lectura estructural de la novela según la configuración de la forma sonata aplicable al allegro o primer movimiento de esta forma musical, no como propuesta interpretativa, sino como hipótesis genealógica de la obra. Los asideros empíricos que toma son de una solidez cuestionable: un argumento textual en la mención por parte de Tristana de las sonatas de Beethoven en el momento de su sedación; la similitud constructiva con otras novelas del autor, y una razón codicológica, en la presencia de "a musical staff with notes [...] in the middle of page seven" (p. 84) en el manuscrito original.

2 Tampoco sorprende, en este sentido, que se compartan incluso metáforas como la del papel en blanco, que representa la escritura como espacio de afirmación del yo y su cese como sinónimo del sacrificio, de la reabsorción por parte de la vorágine social que trasunta la muerte en un plano simbólico (véase Aizenberg, 1985, p. 544; Gold, 1993, p. 644 y Ramírez López, 2009, p. 64).

3 También se alude al físico de Tristana como "fiel imagen de dama japonesa de alto copete" (Pérez Galdós, 2003, p. 7), que más adelante es "figura japonesa" (Pérez Galdós, 2003, p. 77), de "nacarado rostro de dama japonesa" contrapuesto a la "inteligencia soberana" y "viveza de espíritu" (Pérez Galdós, 2003, p. 92) que muestran sus ojos, así como por último "damita japonesa" (Pérez Galdós, 2003, p. 101).

4 En cierta manera, María Eugenia ha asimilado esa veta del pensamiento romántico que no opone a los principios de la razón el discurso sentimental, sino que lo sintetiza con ellos. De acuerdo con González Subías (2007, p. 225), en el Romanticismo se presencia "la aparición de una nueva época, impulsada por los principios de la Ilustración y centrada en el hombre, cuyas señas de identidad son la libertad, la pasión y el sentimiento". De ahí que resulte imposible relegar a la esfera de la unicidad hermética la literatura ilustrada, que se revela como un complejo de corrientes heterogéneas en constante debate y evolución del que participan muchos de los motivos que se trasladan a posteriores movimientos, y que en el Romanticismo no se deba ver sino su consecuencia lógica, la puesta en práctica y posterior fracaso de esos ideales. Aunque muy posterior, la deuda con el Romanticismo se presenta, en este caso, con bastante claridad. 